\title{
Forelimb preferences in human beings and other species: multiple models for testing hypotheses on lateralization
}

\author{
Elisabetta Versace* and Giorgio Vallortigara* \\ Animal Cognition and Neuroscience Laboratory, Center for Mind/Brain Sciences, University of Trento, Rovereto, Italy
}

\section{Edited by:}

Miriam Ittyerah, Institute of Communicative and Cognitive Neurosciences, India

Reviewed by:

Sina Radke, University Hospital RWTH Aachen, Germany

Jacqueline Fagard, University Paris

Descartes, France

*Correspondence:

Elisabetta Versace and Giorgio Vallortigara, Animal Cognition and Neuroscience Laboratory, Center for Mind/Brain Sciences, University of Trento, Piazza della Manifattura 1, Rovereto 38068, Italy e-mail: elisabetta.versace@unitn.it; giorgio.vallortigara@unitn.it
Functional preferences in the use of right/left forelimbs are not exclusively present in humans but have been widely documented in a variety of vertebrate and invertebrate species. A matter of debate is whether non-human species exhibit a degree and consistency of functional forelimb asymmetries comparable to human handedness. The comparison is made difficult by the variability in hand use in humans and the few comparable studies conducted on other species. In spite of this, interesting continuities appear in functions such as feeding, object manipulation and communicative gestures. Studies on invertebrates show how widespread forelimb preferences are among animals, and the importance of experience for the development of forelimb asymmetries. Vertebrate species have been extensively investigated to clarify the origins of forelimb functional asymmetries: comparative evidence shows that selective pressures for different functions have likely driven the evolution of human handedness. Evidence of a complex genetic architecture of human handedness is in line with the idea of multiple evolutionary origins of this trait.

Keywords: forelimb asymmetries, lateralization, handedness, vertebrates, invertebrates, evolution, genetic architecture

\section{FORELIMB PREFERENCES AND HANDEDNESS IN HUMAN BEINGS}

Human beings show a clear functional asymmetry in hand use but its role and origins are still debated. Several studies report a consistent preference for the right hand for different tasks in different cultures and societies (e.g., Porac and Coren, 1981; Annett, 1985, 2002; Perelle and Ehrman, 1994; Raymond and Pontier, 2004). This population-level pattern has been referred to as handedness (Marchant and McGrew, 1998), as opposed to right-left hand preferences that fluctuate in time or between individuals and tasks. In this paper we will refer to this definition of handedness, although it must be noticed that a certain degree of context dependency has been noted for motor dominance (Calvert and Bishop, 1998; Leconte and Fagard, 2006). A bias as strong as $90 \%$ in favor of right handedness is commonly reported for our species (McManus, 2002).

This scenario has encouraged researchers in investigating the origins and functions of handedness for centuries (Rogers et al., 2013). It has been initially suggested that functional asymmetries might be a human-specific trait (Annett, 1995) but empirical evidence has contradicted this hypothesis. Across more than one hundred non-human vertebrate species, about $70 \%$ show limb preferences (Ströckens et al., 2013). Several studies have identified behavioral limb asymmetries in invertebrates too (Frasnelli et al., 2012), although this taxon has been explored to less extent. To summarize a large corpus of studies, asymmetries in limb use have been extensively documented in such a variety of taxa and species that they are clearly not restricted to humans or their proximate relatives. A matter of debate is whether non-human species exhibit a degree and consistency of functional forelimb asymmetries comparable to human handedness. Assuming a 9:1 right-left handedness ratio in humans, other species appear less strongly lateralized (Ströckens et al., 2013), but the pattern of human handedness though is more complex than often reported.

First, several concerns have been raised on the methodology commonly used to assess human handedness (e.g., Marchant et al., 1995; Marchant and McGrew, 1998). In most cases it has been evaluated through self-report questionnaires (Annett, 1970; Oldfield, 1971; Steenhuis et al., 1990). Some questionnaires have demonstrated consistency in time and a good correlation to behavioral measures (Raczkowski et al., 1974; Coren and Porac, 1978) but it should be noticed that the use questionnaires can enhance a response bias. Moreover, these surveys assay culturalspecific activities, such as writing or drawing, and the use of functional objects: throwing a ball, using scissors, a toothbrush, knife and fork, a spoon, a broom, a racket, a shovel, striking a match, opening a box, dealing cards, hammering, unscrew a jar. The exclusion of non-literate societies, and the focus on fine movement and object manipulation can produce an overestimation of the right bias. Moreover, these activities cannot be assessed in non-human animals, thus constraining the possibility of interspecific comparisons. More realistic and comparable evaluations of human handedness should focus on the observation of naturalistic spontaneous behaviors (e.g., Meunier et al., 2012) but few studies have been conducted along this line. Direct observation of spontaneous behaviors in three non-literate societies has 
revealed an overall frequency of $84 \%$ right handedness for tool use, whereas in other actions individuals were mixed-handed and there was an overall right bias of about 55\% (Marchant et al., 1995). Evidence for forelimb asymmetries in self-directed behaviors in other primates are less than conclusive but point at a role of emotions and/or difficulty of the task: some studies reported no population-level asymmetries in great apes (Aruguete et al., 1992; Hopkins and de Waal, 1995; Marchant and McGrew, 1996), others a left-hand bias for face touching in orang-utans, gorillas and chimpanzees (Dimond and Harries, 1984) or a tendency to perform more self-directed behaviors with the right hand in more difficult tasks in chimpanzees (Leavens et al., 2001) and a right preference for combined hand and foot responses directed to the body in squirrel monkeys (Aruguete et al., 1992).

Second, considerable evidence shows time and space variability in human handedness - that in some cases has been related to cultural differences (De Agostini et al., 1997; Mandal, 1999; Dahmen and Fagard, 2005; Kushner, 2013)_, as well as inconsistencies between methods used to assess and report it. Stock et al. (2013) and Marchant and McGrew (1998) have reviewed the existent literature concluding that in Western societies the prevalence of reported left-handers varies between 2 and 13\%, whereas in other cultures from 2 to $27 \%$ (see Faurie et al., 2002 for functional specialization in traditional societies). Similarly, skeletal analysis on thirteen hunter-gatherers populations, Medieval British and 18-19th century British individuals (Stock et al., 2013) has confirmed a large variability in right-biased asymmetry in upper limb morphology. These measures were conducted on the most sensitive regions of the skeleton, that reflect habitual behavior and lateralization. In particular, in the second metacarpal the hunter-gatherers show only $62.5 \%$ right bias [a value lower than observed in chimpanzees (Sarringhaus et al., 2005)], whereas the Medieval and the 18-19th century British groups display a right bias higher than $80 \%$. Referring to the remote past, fossil and archeological records show a proportion of 8-20\% left-handers for Homo neanderthalensis (Uomini, 2011).

To summarize, historical records, direct observations, anatomical, fossil and archeological evidence confirm the presence of right handedness in our species. This evidence though shows also temporal and spatial variability in the prevalence and/or assessment of this trait. It is important to take the variability of human handedness into account to compare this trait with forelimb preferences in other species.

\section{FORELIMB PREFERENCES IN INVERTEBRATES: EVIDENCE IN ARTHROPODS}

Mounting evidence (reviewed in Vallortigara et al., 1999; Vallortigara, 2000; Vallortigara and Bisazza, 2002; MacNeilage et al., 2009) indicates that cerebral lateralization for specific capabilities has appeared before the emergence of vertebrates. How ancient are the origins of forelimb asymmetries has not yet been fully clarified, but they have been documented in different invertebrate species. In particular, arthropods exhibit forelimb asymmetries at the anatomical (Palmer, 2009; Daugeron et al., 2011) and functional level (see Ruppert et al., 2004; Frasnelli et al., 2012).

In crustaceans with asymmetric forelimbs, each claw is specialized for determined motor actions and functions such as fight, attracting females (Govind and Blundon, 1985; Oliveira and Custodio, 1998), grip, hold, grasp, pull, cut during feeding (Hartman et al., 1997). Moreover, the strength of the crusher claw in blue crabs is significantly greater than in the other cutter claw (Govind and Blundon, 1985). But in species without macroscopic anatomical differences the evidence for side preferences and specialization is indirect or restricted to few tasks and motor actions. Studying desert locusts, Bell and Niven (2014) have recently detected individual level asymmetries in the forelimb used to reach across a gap. These asymmetries though are contextdependent and cannot be assimilated to handedness.

In field-collected spitting spiders, Ades and Ramires (2002) have found more frequent left leg losses (likely due to predation), and a left population level asymmetry for assessing preys has been found in the laboratory. In this task the bias was larger in the foremost limb. The larger left leg damage observed in many arachnid species (Heuts and Lambrechts, 1999) suggests that this bias can be widespread but little is known on side and degree of asymmetries in different tasks. Limb asymmetries have been documented in octopuses too (Byrne et al., 2006): wildcollected octopuses prefer using the anterior arms to reach for and explore objects and show left-right preferences at the individual level. These promising findings provide evidence for limbspecialization but investigation in different contexts is needed to clarify the generality of the preference.

Studies on invertebrates are important to understand the ontogeny of limb asymmetries and the role of environmental influences (Palmer, 2012). American lobsters display a random pattern of individual asymmetries in their claws, so that half have the large crusher claw on the left side. In a series of studies, (Govind, 1992, 1984) showed how differential claw use by juveniles induces one claw to transform into a specialized crusher claw, whereas insufficient stimulation during a critical developmental window causes no specialization. These findings show how important behavior can be in inducing and orienting morphological, and subsequently functional, asymmetry.

At present, a comparison between forelimb preferences in invertebrates and human handedness is difficult due to the limited number of studies conducted on invertebrate species and lack of data collected in different contexts within single species. This fact, together with the relative simplicity of the invertebrate nervous system, ease of maintenance, ecological and social differences between closely related species, make this taxon a treasure trove to investigate the evolutionary, genetic and developmental basis of forelimb asymmetries.

\section{FORELIMB PREFERENCES IN VERTEBRATES: DIFFERENT SPECIES FOR TESTING DIFFERENT HYPOTHESES}

The interest for the origin of forelimb preferences and human handedness has motivated a large amount of studies on limb preferences in vertebrates (reviewed in Hopkins, 2006; Vallortigara et al., 2011; Rogers et al., 2013; Ströckens et al., 2013). It has been suggested that forelimb preferences might originate from a functional specialization in the use of hands/paws/forelimbs, such as feeding, tool use or communication; derive from other lateralized functions, for instance dealing with social life, emotions and stress; be a side effect of anatomic asymmetries, developmental or 
genetic constraints; be produced by a combination of the above options.

The choice of which model system choose to test different hypotheses on the origin of forelimb asymmetries is related to the ecology, behavioral habits and phylogeny of the species. Studies focused on non-human primates have a great potential to help tracking the evolutionary history of human handedness by looking at similarities and differences across species closely related to our own. Studies on more phylogenetically distant species might clarify the issue of lineage-specificity of forelimb asymmetries and the role of ecological, social and behavioral traits in determining functional forelimb asymmetries. In the last years researchers have paid more and more attention in assessing forelimb asymmetries in a variety of tasks. These data are crucial to understand the complex scenario of forelimb preferences.

\section{FEEDING, TOOL-USE, BIMANUAL ACTIONS, AND TASK DEMANDS}

Researchers have investigated whether brain hemispheres show a specialization for feeding that can reflect on hand preferences. Andrew (2002) has proposed that lateralization has emerged in the earliest vertebrates, whose mouth was located on the left side of the head, for perceptual and motor control of feeding. In line with this idea, a bias for the use of right organs (e.g., eye, forelimb, hand and jaw used in feeding) controlled by the left brain hemisphere has been identified in all vertebrate classes: fishes (De Santi et al., 2002), amphibians (toads: Bisazza et al., 1996), amphibians (Vallortigara et al., 1998), birds (Friedmann and Davis, 1938; Rogers, 1980; Tommasi and Vallortigara, 1999), mammals (for marsupials see, Giljov et al., 2012), for non-primate mammals (e.g., Clapham et al., 1995), for non-human primates (reviewed in Hopkins, 2006). While investigating forelimb asymmetries in feeding, it has been noticed that in primates simple unimanual behaviors enhance a weaker degree of handedness than bimanual behaviors that require coordination of a supporting and a manipulating hand. This pattern is consistent with the task complexity hypothesis (Fagot and Vauclair, 1991): according to this model, simple tasks as basic unimanual reaching induce weaker lateralized responses than high-level tasks as bimanual coordination. It has been proposed that demanding tasks enhance lateralized preferences, as observed for instance in cats (Wells and Millsopp, 2009). The strong pattern of foot preferences for food holding observed in Australian parrots is consistent with this hypothesis: eight out of nine investigated species exhibited a significant population preference for using the left foot and one species for the right foot, with a strength of lateralization up to 90\% (Rogers, 1980). Brown and Magat (2011) documented a correlation between foraging mode and footedness, with birds that extract seeds from seedpods using coordinated foot-beak actions being stronger lateralized than birds feeding on small grass seeds and blossoms, that are normally eaten without using a claw. These data suggest the importance of ecological pressures to shape lateralization in limb use, not specifically to forelimbs.

But the demands in terms of hemispheric specialization might be more important than task's complexity (Rogers, 2009). Along this line, Forrester et al. (2013) have found that children, chimpanzees (Forrester et al., 2012) and gorillas (Forrester et al., 2011) exhibit stronger right lateralization in response to inanimate objects (non-living functional objects) but not to animate objects (social partner, self). Hence dealing with functional objects would activate the left hemisphere, enhancing a right-hand bias in primates that inherited a left-hemisphere specialization for tool-use (Forrester et al., 2013).

It has been hypothesized that human right-handedness derives from a selective pressure for tool use (Breuer et al., 2005; Greenfield, 2011) or coordinated bimanual actions (Wundram, 1986; Bradshaw and Rogers, 1993; Hopkins et al., 2003) and that has been inherited from an ancestor in common with apes. The continuity for bimanual coordinated actions between Old world monkeys (e.g., Vauclair et al., 2005), great apes (e.g., Hopkins, 1995) and humans (Fagard and Marks, 2000; Jacquet et al., 2012) has a strong empirical support (Meguerditchian et al., 2013 review evidence on baboons, rhesus monkeys, chimpanzees, bonobos, gorillas, human infants). Hopkins (2006) suggested that bimanual coordinated activities may have driven the evolution of human handedness more than the mere tool-use. Variations of the postural and biomechanical factors related to the ecology of the species (i.e., arboreal vs. terrestrial species) may constitute another major factor in addition to the complexity of the manual behaviors for explaining the phylogenetic distribution.

Summarizing, empirical evidence suggests that righthandedness in primates is influenced by brain specialization for feeding, tool-use and coordinated bimanual actions, and that it is enhanced by the demands imposed by the task. To date little evidence for presence or absence of limb lateralization in feeding, bimanual actions or tool-use has been reported outside the primate order. This prevents us to test the idea that handedness in tool-use and bimanual coordinated actions has specifically emerged in the primate lineage. Interestingly though, corvids show individual level lateralization for tool-use (Weir et al., 2004) and a population right bias for tool-making (Hunt et al., 2001). Further investigation on marsupials with different postural habits can also shed light into the role of tool use and bimanual coordination in handedness.

\section{RELATION TO LANGUAGE, GESTURE AND COMMUNICATION}

Although both right- and left-handers are to a large extent lateralized for language on the left hemisphere (Ocklenburg et al., 2014b), right-handed individuals are more likely to have the left hemisphere dominant for language than left-handed ones (95 to 70-85\%) (Knecht et al., 2000; Perlaki et al., 2013).

For instance Knecht et al. (2000) found an increase of righthemisphere dominance as a function of the degree of lefthandedness. The association between hemispheric dominance for language and handedness has suggested that language and handedness coevolved as human-specific traits (Annett, 1985; Corballis, 2002). Yet, evidence on population-level limb asymmetries in species far related from humans can contradict this uniqueness hypothesis. Population-level asymmetries in limb use have emerged for instance in toads (Bisazza et al., 1996), that prefer to use the right paw to remove materials from their body and to rotate from the upside-down position. This evidence, together with population-level asymmetries detected in other species (Ströckens et al., 2013), shows that owning language is not necessary to show population-level limb preferences. 
Interspecific comparisons can help clarifying whether righthandedness evolved together with a left-hemisphere specialization for communicative abilities (Corballis, 2002). Meunier et al. (2012) have used the same test to investigate communicativeassociated forelimb preferences in 14-20 month-old human infants and baboons showing for both species a significantly stronger right bias for the communicative task than for grasping. Meguerditchian et al. (2013) have recently reviewed the studies that investigated the involvement of the left hemisphere in gestural communication in human and non-human primates. Right-handedness in our species is associated with communicative gestures such as signing in deaf (Vaid et al., 1989; Grossi et al., 1996), hand movements during conversations (Kimura, 1973), pointing in infants and toddlers (Blake et al., 1994; Jacquet et al., 2012). During development, the connection between communicative gestures and right-handedness is stronger than for non-communicative manual actions (Bates et al., 1986; Cochet and Vauclair, 2010; Jacquet et al., 2012): this evidence suggests a possible independence between communicative and noncommunicative actions (see Jacquet et al., 2012; Ocklenburg et al., 2014b). Moreover, an integration between speech and gestural communication has been documented in the activation of different brain areas (Corina et al., 2003; Emmorey et al., 2007; Willems et al., 2007; Andric et al., 2013).

Studying non-human primates can help identifying the existence of left-hemispheric specialization for communication and prerequisites of language. Studies with large samples of non-human primates have consistently reported a pronounced population-level right-handedness for different gestures (see Meguerditchian et al., 2013 for a recent review). Interestingly, the degree of right-handedness was higher for gestural communication than for other actions. Overall, these findings confirm the continuity between humans and other primates in left hemispheric specialization for communication. It has been suggested that this lateralized system, shared by a common ancestor of humans and apes, would be a prerequisite for language dated at least 30-40 million years ago (Meguerditchian and Vauclair, 2006).

\section{RELATION TO BIPEDAL POSTURE}

After MacNeilage (MacNeilage et al., 1987; MacNeilage, 2007) proposed the postural origin theory, several authors (e.g., Westergaard et al., 1998; Corbetta, 2003) have hypothesized a relation between handedness and the acquisition of bipedalism, with upright posture facilitating object manipulation and manual laterality. In agreement with this hypothesis, growing evidence shows an effect of posture (body orientation and postural habit) on manual laterality in non-human primates as well as marsupials, with the presence of stronger lateralization in forelimb use for higher degree of bipedalism.

Upright posture correlates with increased side preference in hand use in many species of prosimians, monkeys and apes (critically reviewed, in Hopkins et al., 2011; Giljov et al., 2012), an effect that could be connected to the increase of manual skills with upright posture. The strength of laterality increases from the strongly quadrupedal mouse lemurs to the more bipedal galagos. In apes, species with higher bipedality such as chim- panzees and bonobos tend to have stronger manual preferences than more quadrupedal species such as gorillas and orang-utans. Gorillas and gibbons, described as more bipedal than orangutans, are more likely to express population-level lateralization in hand use.

In the last decade the relation between body posture and forelimb preferences has been investigated in lineages other than primates. These studies are important to clarify whether this phenomenon has emerged exclusively in the primate lineage. In analogy with quadrupedal prosimians, two obligatory quadrupedal species, domestic cats (Konerding et al., 2012) and the tree shrews (Joly et al., 2012), are not affected by the postural demands of the task (sitting or standing) in either direction or strength of paw preferences while reaching for food. Due to the variety of postural habits, marsupials are convenient models to study the relation between posture and forelimb preferences. Marsupial quadruped species show no population-level bias in forelimb use (Giljov et al., 2013), contrary to the primary bipedal red-necked wallabies (Giljov et al., 2012). In a mostly bipedal marsupial, the brushtailed bettong, a left forelimb preference has been documented in all studied unimanual behaviors (Giljov et al., 2012).

Summarizing, in non-human primates and marsupials the between-species pattern indicates that the proportion of lateralized individuals and the strength of forelimb preferences tend to increase with more vertical and bipedal species-typical posture. These findings confirm the hypothesis that species postural characteristics influence manual laterality beyond the order of primates.

\section{LEFT-HANDEDNESS}

Forelimb asymmetries are defined as a relative measure between right and left side. In the previous sections we have seen how right-handedness at least partially reflects the specialization of the left hemisphere for feeding, tool-use, bimanual coordination and communication. In our species, documented (but in some cases weak) differences between left- and right-handed individuals and strong $v s$. weak lateralization include general cognitive ability (Nettle, 2003; Nicholls et al., 2010), personality (Grimshaw and Wilson, 2013), motivation (Brookshire and Casasanto, 2012), perception (Ocklenburg et al., 2010), language (Knecht et al., 2000). Differences between right- and left- handed individuals have been found in non-human primates as well.

Looking at marmosets, Rogers and collaborators (Cameron and Rogers, 1999; Gordon and Rogers, 2010) have shown a connection between handedness and cognitive styles: left-handed marmosets are less explorative in unfamiliar environments and less prompt in showing social facilitation of feeding responses. In rhesus macaques Westergaard et al. (2003) have found that righthanded males, contrary to females, receive more aggressive interactions and less grooming from conspecifics and they are more likely to be submissive (see Howell et al., 2007). To understand forelimb preferences, the connection between left forelimb use and left-hemisphere specialization must be explained.

Several studies show that the activity of the right hemisphere is associated with detecting and responding to unexpected and possibly threatening stimuli, including fear and aggressive responses (Rogers and Andrew, 2002; MacNeilage et al., 2009; 
Rogers, 2009, 2002). Hence tasks performed by right-handed people with the left hand might reflect the activity of the right hemisphere. Researchers have surveyed large samples of human beings involved in sport activities to look for tasks in which the use of the left hand might be over-represented and found confirming evidence of an overrepresentation of left-handers in interacting sports (Goldstein and Young, 1996; Brooks et al., 2004; Loffing and Hagemann, 2014; Loffing et al., 2014). Based on the proportion of left-handed individuals in interactive sports, Raymond et al. (1996) have proposed that left-handed individuals have a frequency-dependent advantage in fighting. This advantage would maintain a proportion of left-handed individuals in the population as a result of an evolutionarily stable strategy (Ghirlanda and Vallortigara, 2004). Along a similar line, a correlation between the degree of left-handedness and homicide rates has been found, although these data can have several explanations (Faurie and Raymond, 2005).

Left-handedness or reduced right-handedness are linked also to some traits with clinical relevance such as depression (Denny, 2009), schizophrenia (Sommer et al., 2001; Dragovic and Hammond, 2005), higher (but nor pathological) alcohol consumption (Denny, 2011), immune response (Stoyanov et al., 2011), while a reduced right-handedness and inconsistent laterality can accompany specific pathological phenotypes (Carlier et al., 2006; Gérard-Desplanches et al., 2007). Interestingly the association between forelimb asymmetries and modulation of immune response has been found in different species: left-pawded mice show higher phytohemagglutinin- and concanavalin- induced proliferation (Neveu et al., 1988). Abramov et al. (2001) observed that in left-pawded mice thymocytes from the left lobe of thymus have higher concanavalin-stimulated proliferation than those from the right lobe, and right-pawded mice show the reversed pattern. Quaranta et al. (2004) found in left-pawed dogs higher percentage and number of lymphocytes and lower percentages of granulocytes and lower number of $\gamma$-globulins compared to right-pawed and ambidextrous dogs. Overall, left hemispheric activation associated to right forelimb preference seems to produce either greater production of stress hormones or greater reactivity to stress that enhances immune response, as confirmed by the negative correlation between right-hand preference and stress reactivity in rhesus macaques (Westergaard et al., 2001). Interestingly, limb preferences are sensitive to experience and can even reflect the tendency toward positive or negative cognitive bias (Rogers, 2010), thus showing the importance of the environment in assessing forelimb asymmetries.

\section{GENETIC ARCHITECTURE OF FORELIMB PREFERENCES}

The heritability pattern of human handedness-e.g., familial history of left-handedness (Annett, 1973; Medland et al., 2010), higher concordance of handedness for monozygotic than dizygotic twins (McManus and Bryden, 1992)—suggests a genetic control of this trait. While reviewing different hypotheses about the origin of handedness and forelimb preferences we have showed that selective pressures for different functions-e.g., tool-use, communication, bipedal posture/task complexity, stress responsiveness-have likely influenced the evolution of forelimb preferences. This multifactorial pattern might reflect a complex genetic architecture of forelimb asymmetries.

The first models of the inheritance of handedness have hypothesized a simple genetic basis of this trait, with a single causative locus with two or more alleles or two loci involved (e.g., Levy and Nagylaki, 1972; Annett, 2002; McManus, 2010). Heritability estimates do not contradict these models (Annett, 1985; Klar, 1996). Such a simple genetic architecture was expected to be identified using traditional molecular approaches or genomewide association studies. But as reviewed in McManus et al. (2013), to date no associations have been replicated across studies, and in several studies only marginally significant results or no significant associations have been found, even in the presence of large samples (Armour et al., 2014). This pattern of results provides indirect evidence of a complex genetic architecture (Rockman, 2012; Mackay, 2014). Moreover, by screening individuals with pathological conditions several loci have been associated with handedness (Ocklenburg et al., 2014b; reviewed in Brandler and Paracchini, 2014), in particular for dyslexia (Scerri et al., 2011; Brandler et al., 2013) and schizophrenia (Francks et al., 2007), thus providing some support to the polygenic basis of handedness. Genetic linkage studies have also identified different genomic regions connected to handedness [for instance the markers 2p12-q11 (Francks et al., 2002, 2003) and 12q21-23 (Warren et al., 2006)], but little is known about the role of orthologs/homologs in non-human species. In the light of genetic evidence, multi-locus models (McManus et al., 2013) and multilocus models with partial pleiotropy (Ocklenburg et al., 2014b) have been suggested to explain handedness, but the underlying basis of handedness remains to a large extent elusive.

Understanding the molecular basis of functional asymmetries may help reconstructing the causative relationship between lateralization and specific phenotypes (Bishop, 2013), for instance to understand whether weak laterality is the cause or effect of some neurodevelopmental disorders or the same genetic basis underlies both phenotypes. Given the widespread presence of functional asymmetries in limb use in non-human species (see previous sections), one might wonder why the investigation of the underlying genetics of handedness has not been pursued in model species for which genetic tools are easily accessible such as Drosophila or mice. Anatomical and functional asymmetries have been identified in the nervous system of fruit flies (Pascual et al., 2004) and in mice the strength of lateralization has a genetic component (Collins, 1968; Biddle and Eales, 1996, 1999). The murine model species though do not apparently exhibit a population level parallel of human handedness. This consideration should not necessarily constrain the investigation of functional asymmetries in other species, especially considering that even in our species forelimb asymmetries can vary due to cultural, ecological and task/function demands. Since human handedness is correlated with cerebral asymmetry, and genes involved in the development of left-right asymmetry are widespread among different species, left-right asymmetry genes might be considered as candidate genes to investigate more specific domains of lateralization such as forelimb asymmetries. For instance, the marker associated to hand skill and dyslexia rs11855415 (Scerri et al., 2011; Brandler et al., 2013) is connected to the Nodal pathway, which is known 
to determine the development of left/right asymmetries in a wide range of species (Bamford et al., 2000; Concha et al., 2000; Mercola and Levin, 2001; Grande and Patel, 2009). Interestingly, when expression of this pathway is absent, structural asymmetries in zebrafish are maintained but they are random in direction (Concha et al., 2000). The Nodal pathway can be also involved in the development of human handedness (Brandler and Paracchini, 2014), for which it has been argued that direction and strength of biases may represent independent phenotypes (Ocklenburg et al., 2014a).

It is thus apparent that a convergence of data and theories from different disciplines is necessary to elucidate the origins, mechanisms and evolutionary history of limb preferences. In this regard evidence from other species, even those that lack appendages like limbs but that have asymmetries in brain and behavior, such as zebrafish, may ultimately be crucial for deciphering handedness in humans.

\section{REFERENCES}

Abramov, V. V., Gontova, I. A., and Kozlov, V. A. (2001). Functional asymmetry of thymus and the immune response in mice. Neuroimmunomodulation 9, 218224. doi: $10.1159 / 000049029$

Ades, C., and Ramires N. E. (2002). Asymmetry of leg use during prey handling in the spider scytodes globula (Scytodidae). J. Insect Behav. 15, 563-570. doi: 10.1023/A:1016337418472

Andrew, R. J. (2002). "The earliest origins and subsequent evolution of lateralization," in Comparative Vertebrate Lateralization, eds L. J. Rogers and R. J. Andrew (Cambridge: Cambridge University Press), 70-93.

Andric, M., Solodkin, A., Buccino, G., Goldin-Meadow, S., Rizzolatti, G., and Small, S. L. (2013). Brain function overlaps when people observe emblems, speech, and grasping. Neuropsychologia 51, 1619-1629. doi: 10.1016/j.neuropsychologia. 2013.03.022

Annett, M. (1970). A classification of hand preference by association analysis. Br. J. Psychol. 61, 303-321. doi: 10.1111/j.2044-8295.1970.tb01248.x

Annett, M. (1973). Handedness in families. Ann. Hum. Genet. 37, 93-105. doi: 10.1111/j.1469-1809.1973.tb01817.x

Annett, M. (1985). Left, Right, Hand, and Brain: The Right Shift Theory. New Jersey: Lawrence Erlbaum.

Annett, M. (1995). The right shift theory of a genetic balanced polymorphism for cerebral dominance and cognitive processing. Cah. Psychol. Cogn. Psychol. 14, $427-480$.

Annett, M. (2002). Handedness and Brain Asymmetry: The Right Shift Theory. New York: Psycchology Press.

Armour, J. A. L., Davison, A., and McManus, I. C. (2014). Genome-wide association study of handedness excludes simple genetic models. Heredity (Edinb). 112, 221-225. doi: 10.1038/hdy.2013.93

Aruguete, M. S., Ely, E. A., and King, J. E. (1992). Laterality in spontaneous motoractivity of chimpanzees and squirrel-monkeys. Am. J. Primatol. 27, 177-188. doi: 10.1002/ajp.1350270303

Bamford, R. N., Roessler, E., Burdine, R. D., Saplakoğlu, U., dela Cruz, J., Splitt, M., et al. (2000). Loss-of-function mutations in the EGF-CFC gene CFC1 are associated with human left-right laterality defects. Nat. Genet. 26, 365-369. doi: $10.1038 / 81695$

Bates, E., O'Connell, B., Vaid, J., Sledge, P., and Oakes, L. (1986). Language and hand preference in early development. Dev. Neuropsychol. 2, 1-15. doi: 10.1080/ 87565648609540323

Bell, A. T. A., and Niven, J. E. (2014). Individual-level, context-dependent handedness in the desert locust. Curr. Biol. 24, R382-R383. doi: 10.1016/j.cub.2014. 03.064

Biddle, F. G., and Eales, B. A. (1999). Mouse genetic model for left-right hand usage: context, direction, norms of reaction, and memory. Genome 42, 1150-1166. doi: 10.1139/gen-42-6-1150

Biddle, F. G., and Eales, B. A. (1996). The degree of lateralization of paw usage (handedness) in the mouse is defined by three major phenotypes. Behav. Genet. 26, 391-406. doi: 10.1007/BF02359483
Bisazza, A., Cantalupo, C., Robins, A., Rogers, L. J., and Vallortigara, G. (1996). Right-pawedness in toads. Nature 379, 408. doi: 10.1038/379408a0

Bishop, D. V. M. (2013). Cerebral asymmetry and language development: cause, correlate, or consequence? Science 340, 1230531. doi: 10.1126/science.1230531

Blake, J., O'Rourke, P., and Borzellino, G. (1994). Form and function in the development of pointing and reaching gestures. Infant Behav. Dev. 17, 195-203. doi: 10.1016/0163-6383(94)90055-8

Bradshaw, J., and Rogers, L. J. (1993). The Evolution of Lateral Asymmetries, Language, Tool-Use, and Intellect. San Diego: Academic Press.

Brandler, W. M., Morris, A. P., Evans, D. M., Scerri, T. S., Kemp, J. P., Timpson, N. J., et al. (2013). Common variants in left/right asymmetry genes and pathways are associated with relative hand skill. PLoS Genet. 9:e1003751. doi: 10.1371/journal. pgen.1003751

Brandler, W. M., and Paracchini, S. (2014). The genetic relationship between handedness and neurodevelopmental disorders. Trends Mol. Med. 20, 83-90. doi: 10.1016/j.molmed.2013.10.008

Breuer, T., Ndoundou-Hockemba, M., and Fishlock, V. (2005). First observation of tool use in wild gorillas. PLoS Biol. 3:e380. doi: 10.1371/journal.pbio.0030380

Brooks, R., Bussière, L. F., Jennions, M. D., and Hunt, J. (2004). Sinister strategies succeed at the cricket World Cup. Proc. R. Soc. B Biol. Sci. 271(Suppl.), S64-S66. doi: 10.1098/rsbl.2003.0100

Brookshire, G., and Casasanto, D. (2012). Motivation and motor control: hemispheric specialization for approach motivation reverses with handedness. PLoS ONE 7:e36036. doi: 10.1371/journal.pone.0036036

Brown, C., and Magat, M. (2011). The evolution of lateralized foot use in parrots: a phylogenetic approach. Behav. Ecol. 22, 1201-1208. doi: 10.1093/beheco/arr114

Byrne, R. A., Kuba, M. J., Meisel, D. V., Griebel, U., and Mather, J. A. (2006). Does Octopus vulgaris have preferred arms? J. Comp. Psychol. 120, 198-204. doi: 10.1037/0735-7036.120.3.198

Calvert, G. A., and Bishop, D. V. (1998). Quantifying hand preference using a behavioural continuum. Laterality 3, 255-268. doi: 10.1080/713754307

Cameron, R., and Rogers, L. J. (1999). Hand preference of the common marmoset (Callithrix jacchus): problem solving and responses in a novel setting. J. Comp. Psychol. 113, 149-157. doi: 10.1037/0735-7036.113.2.149

Carlier, M., Stefanini, S., Deruelle, C., Volterra, V., Doyen, A. L., Lamard, C., et al. (2006). Laterality in persons with intellectual disability. I-do patients with trisomy 21 and Williams-Beuren syndrome differ from typically developing persons? Behav. Genet. 36, 365-376. doi: 10.1007/s10519-006-9048-9

Clapham, P. J., Leimkuhler, E., Gray, B. K., and Mattila, D. K. (1995). Do humpback whales exhibit lateralized behaviour? Anim. Behav. 50, 73-82. doi: 10.1006/anbe. 1995.0222

Cochet, H., and Vauclair, J. (2010). Pointing gesture in young children: hand preference and language development. Gesture 10, 129-149. doi: 10.1075/gest.10.2$3.02 \mathrm{coc}$

Collins, R. L. (1968). On the inheritance of handedness. J. Hered. 59, 9-12.

Concha, M. L., Burdine, R. D., Russell, C., Schier, A. F., and Wilson, S. W. (2000). A nodal signaling pathway regulates the laterality of neuroanatomical asymmetries in the zebrafish forebrain. Neuron 28, 399-409. doi: 10.1016/S08966273(00)00120-3

Corballis, M. C. (2002). From Hand to Mouth: The Origins of Language. Princeton: Princeton University Press.

Corbetta, D. (2003). Right-handedness may have come first: evidence from studies in human infants and nonhuman primates. Behav. Brain Sci. 26, 217-218. doi: 10.1017/S0140525X03320060

Coren, S., and Porac, C. (1978). The validity and reliability of self-report items for the measurement of lateral preference. Br. J. Psychol. 69, 207-211. doi: 10.1111/j.2044-8295.1978.tb01649.x

Corina, D. P., San Jose-Robertson, L., Guillemin, A., High, J., and Braun, A. R. (2003). Language lateralization in a bimanual language. J. Cogn. Neurosci. 15, 718-730. doi: 10.1162/089892903322307438

Dahmen, R., and Fagard, J. (2005). The effect of explicit cultural bias on lateral preferences in Tunisia. Cortex 41, 805-815. doi: 10.1016/S0010-9452(08) 70299-5

Daugeron, C., Plant, A., Winkler, I., Stark, A., and Baylac, M. (2011). Extreme male leg polymorphic asymmetry in a new empidine dance fly (Diptera: Empididae). Biol. Lett. 7, 11-14. doi: 10.1098/rsbl.2010.0726

De Agostini, M., Khamis, A. H., Ahui, A. M., and Dellatolas, G. (1997). Environmental influences in hand preference: an african point of view. Brain Cogn. 35, 151-167. doi: 10.1006/brcg.1997.0935 
Denny, K. (2009). Handedness and depression: evidence from a large population survey. Laterality 14, 246-255. doi: 10.1080/13576500802362869

Denny, K. (2011). Handedness and drinking behaviour. Br. J. Health Psychol. 16, 386-395. doi: 10.1348/135910710X515705

De Santi, A., Bisazza, A., and Vallortigara, G. (2002). Complementary left and right eye use during predator inspection and shoal-mate scrutiny in minnows. J. Fish Biol. 60, 1116-1125. doi: 10.1111/j.1095-8649.2002.tb01708.x

Dimond, S., and Harries, R. (1984). Face touching in monkeys, apes and man: evolutionary origins and cerebral asymmetry. Neuropsychologia 22, 227-233. doi: 10.1016/0028-3932(84)90065-4

Dragovic, M., and Hammond, G. (2005). Handedness in schizophrenia: a quantitative review of evidence. Acta Psychiatr. Scand. 111, 410-419. doi: 10.1111/j.16000447.2005.00519.x

Emmorey, K., Mehta, S., and Grabowski, T. J. (2007). The neural correlates of sign versus word production. Neuroimage 36, 202-208. doi: 10.1016/j.neuroimage. 2007.02.040

Fagard, J., and Marks, A. (2000). Unimanual and bimanual tasks and the assessment of handedness in toddlers. Dev. Sci. 3, 137-147. doi: 10.1111/1467-7687.00107

Fagot, J., and Vauclair, J. (1991). Manual laterality in nonhuman primates: a distinction between handedness and manual specialization. Psychol. Bull. 109, 76-89. doi: 10.1037/0033-2909.109.1.76

Faurie, C., and Raymond, M. (2005). Handedness, homicide and negative frequencydependent selection. Proc. Biol. Sci. 272, 25-28. doi: 10.1098/rspb.2004.2926

Faurie, C., Schiefenhovel, W., Le Bomin, S., Billiard, S., and Raymond, M. (2002). Variation in the frequency of left handedness in traditional societies. Curr. Anthropol. 46, 142-147. doi: 10.1086/427101

Forrester, G. S., Leavens, D. A., Quaresmini, C., and Vallortigara, G. (2011). Target animacy influences gorilla handedness. Anim. Cogn. 14, 903-907. doi: 10.1007/ s10071-011-0413-6

Forrester, G. S., Quaresmini, C., Leavens, D. A., Mareschal, D., and Thomas, M. S. C. (2013). Human handedness: an inherited evolutionary trait. Behav. Brain Res. 237, 200-206. doi: 10.1016/j.bbr.2012.09.037

Forrester, G. S., Quaresmini, C., Leavens, D. A., Spiezio, C., and Vallortigara, G. (2012). Target animacy influences chimpanzee handedness. Anim. Cogn. 15, 1121-1127. doi: 10.1007/s10071-012-0536-4

Francks, C., DeLisi, L. E., Fisher, S. E., Laval, S. H., Rue, J. E., Stein, J. F., et al. (2003). Confirmatory evidence for linkage of relative hand skill to 2p12-q11. Am. J. Hum. Genet. 72, 499-502. doi: 10.1086/367548

Francks, C., Fisher, S. E., MacPhie, I. L., Richardson, A. J., Marlow, A. J., Stein, J. F., et al. (2002). A genomewide linkage screen for relative hand skill in sibling pairs. Am. J. Hum. Genet. 70, 800-805. doi: 10.1086/339249

Francks, C., Maegawa, S., Laurén, J., Abrahams, B. S., Velayos-Baeza, A., Medland, S. E., et al. (2007). LRRTM1 on chromosome 2 p12 is a maternally suppressed gene that is associated paternally with handedness and schizophrenia. Mol. Psychiatry 12, 1129-1139. doi: 10.1038/sj.mp.4002053

Frasnelli, E., Vallortigara, G., and Rogers, L. J. (2012). Left-right asymmetries of behaviour and nervous system in invertebrates. Neurosci. Biobehav. Rev. 36, 1273-1291. doi: 10.1016/j.neubiorev.2012.02.006

Friedmann, H., and Davis, M. (1938). "Left-handedness" in parrots. Auk 80, 478480. doi: $10.2307 / 4078415$

Gérard-Desplanches, A., Deruelle, C., Stefanini, S., Ayoun, C., Volterra, V., Vicari, S., et al. (2007). Laterality in persons with intellectual disability II. Hand, foot, ear, and eye laterality in persons with trisomy 21 and williams-beuren syndrome. Dev. Psychobiol. 48, 82-91. doi: 10.1002/dev.20163

Ghirlanda, S., and Vallortigara, G. (2004). The evolution of brain lateralization: a game-theoretical analysis of population structure. Proc. R. Soc. B Biol. Sci. 271, 853-857. doi: 10.1098/rspb.2003.2669

Giljov, A., Karenina, K., and Malashichev, Y. (2012). Does bipedality predict the group-level manual laterality in mammals? PLoS ONE 7:e51583. doi: 10.1371/ journal.pone. 0051583

Giljov, A., Karenina, K., and Malashichev, Y. (2013). Forelimb preferences in quadrupedal marsupials and their implications for laterality evolution in mammals. BMC Evol. Biol. 13:61. doi: 10.1186/1471-2148-13-61

Goldstein, S. R., and Young, C. A. (1996). "Evolutionary" stable strategy of handedness in major league baseball. J. Comp. Psychol. 110, 164-169. doi: 10.1037/07357036.110.2.164

Gordon, D. J., and Rogers, L. J. (2010). Differences in social and vocal behavior between left- and right-handed common marmosets (Callithrix jacchus). J. Comp. Psychol. 124, 402-411. doi: 10.1037/a0019736
Govind, C. K. (1984). Development of asymmetry in the neuromuscular system of lobster claws. Biol. Bull. 167, 94-119. doi: 10.2307/1541340

Govind, C. K. (1992). Claw asymmetry in lobsters: case study in developmental neuroethology. J. Neurobiol. 23, 1423-1445. doi: 10.1002/neu.480231006

Govind, C. K., and Blundon, J. A. (1985). Form and function of the asymmetric chelae in Blue crabs with normal and reversed handedness. Biol. Bull. 168, 321331. doi: $10.2307 / 1541244$

Grande, C., and Patel, N. H. (2009). Nodal signalling is involved in left-right asymmetry in snails. Nature 457, 1007-1011. doi: 10.1038/nature07603

Greenfield, P. M. (2011). Language, tools and brain: the ontogeny and phylogeny of hierarchically organized sequential behavior. Behav. Brain Sci. 14, 531-551. doi: 10.1017/S0140525X00071235

Grimshaw, G. M., and Wilson, M. S. (2013). A sinister plot? Facts, beliefs, and stereotypes about the left-handed personality. Laterality 18, 135-151. doi: 10.1080/1357650X.2011.631546

Grossi, G., Semenza, C., Corazza, S., and Volterra, V. (1996). Hemispheric specialization for sign language. Neuropsychologia 34, 737-740. doi: 10.1016/00283932(96)00008-5

Hartman, H. B., Johnson, E. E., and Storer, P. D. (1997). Manipulation by the crab claw is dependent upon chordotonal organ afference. J. Exp. Zool. 278, 579-586. doi: 10.1002/(SICI) 1097-010X(19971215)279:6<579::AID-JEZ6>3.0. $\mathrm{CO} ; 2-\mathrm{K}$

Heuts, B. A., and Lambrechts, D. Y. M. (1999). Positional biases in leg loss of spiders and harvestmen (Arachnida). Entomol. Ber. 59, 13-20.

Hopkins, W. D. (1995). Hand preferences for a coordinated bimanual task in 110 chimpanzees (Pan troglodytes): cross-sectional analysis. J. Comp. Psychol. 109, 291-297. doi: 10.1037/0735-7036.109.3.291

Hopkins, W. D. (2006). Comparative and familial analysis of handedness in great apes. Psychol. Bull. 132, 538-559. doi: 10.1037/0033-2909.132.4.538

Hopkins, W. D., and de Waal, F. B. M. (1995). Behavioral laterality in captive bonobos (Pan paniscus). J. Comp. Primatol. 16, 261-276. doi: 10.1037/07357036.107.4.403

Hopkins, W. D., Hook, M., Braccini, S., and Schapiro, S. J. (2003). Population-level right handedness for a coordinated bimanual task in chimpanzees: replication and extension in a second colony of apes. Int. J. Primatol. 24, 677-689. doi: 10.1023/A:1023752816951

Hopkins, W. D., Phillips, K. A., Bania, A., Calcutt, S. E., Russell, J., Schaeffer, J., et al. (2011). Hand preferences for coordinated bimanual actions in 777 great apes: implications for the evolution of handedness in hominins. J. Hum. Evol. 60, 605-611. doi: 10.1016/j.jhevol.2010.12.008

Howell, S., Higley, J. D., and Westergaard, G. C. (2007). "The biological correlates of hand preference in rhesus macaques," in The Evolution of Hemispheric Specialization in Primates, ed. W. D. Hopkins (Oxford: Elsevier), 253276.

Hunt, G. R., Corballis, M. C., Gray, R. D., Hoegh-Guldberg, O., Jones, R. J., Ward, S., et al. (2001). Laterality in tool manufacture by crows. Nature 414 , 707. doi: $10.1038 / 414707 \mathrm{a}$

Jacquet, A.-Y., Esseily, R., Rider, D., and Fagard, J. (2012). Handedness for grasping objects and declarative pointing: a longitudinal study. Dev. Psychobiol. 54, 3646. doi: $10.1002 / \mathrm{dev} .20572$

Joly, M., Scheumann, M., and Zimmermann, E. (2012). Posture does not matter! Paw usage and grasping paw preference in a small-bodied rooting quadrupedal mammal. PLoS ONE 7:e38228. doi: 10.1371/journal.pone.0038228

Kimura, D. (1973). Manual activity during speaking- I. right-handers. Neuropsychologia 11, 45-50. doi: 10.1016/0028-3932(73)90063-8

Klar, A. J. (1996). A single locus, RGHT, specifies preference for hand utilization in humans. Cold Spring Harb. Symp. Quant. Biol. 61, 59-65. doi: 10.1101/SQB. 1996.061.01.009

Knecht, S., Dräger, B., Deppe, M., Bobe, L., Lohmann, H., Flöel, A., et al. (2000). Handedness and hemispheric language dominance in healthy humans. Brain 123, 2512-2518. doi: 10.1093/brain/123.12.2512

Konerding, W. S., Hedrich, H.-J., Bleich, E., and Zimmermann, E. (2012). Paw preference is not affected by postural demand in a nonprimate mammal (Felis silvestris catus). J. Comp. Psychol. 126, 15-22. doi: 10.1037/a0024638

Kushner, H. I. (2013). Why are there (almost) no left-handers in China? Endeavour 37, 71-81. doi: 10.1016/j.endeavour.2012.12.003

Leavens, D. A., Aureli, F., Hopkins, W. D., and Hyatt, C. W. (2001). Effects of cognitive challenge on self-directed behaviors by chimpanzees (Pan troglodytes). Am. J. Primatol. 55, 1-14. doi: 10.1002/ajp.1034 
Leconte, P., and Fagard, J. (2006). Which factors affect hand selection in children's grasping in hemispace? Combined effects of task demand and motor dominance. Brain Cogn. 60, 88-93. doi: 10.1016/j.bandc.2005.09.009

Levy, J., and Nagylaki, T. (1972). A model for the genetics of handedness. Genetics 72, 117-128.

Loffing, F., and Hagemann, N. (2014). Pushing through evolution? Incidence and fight records of left-oriented fighters in professional boxing history. Laterality 20, 270-286. doi: 10.1080/1357650X.2014.961471

Loffing, F., Sölter, F., and Hagemann, N. (2014). Left preference for sport tasks does not necessarily indicate left-handedness: sport-specific lateral preferences, relationship with handedness and implications for laterality research in behavioural sciences. PLoS ONE 9:e105800. doi: 10.1371/journal.pone.0105800

Mackay, T. F. C. (2014). Epistasis and quantitative traits: using model organisms to study gene-gene interactions. Nat. Rev. Genet. 15, 22-33. doi: 10.1038/nrg3627

MacNeilage, B. P. F., Rogers, L. J., and Vallortigara, G. (2009). Origins of left and right brain. Sci. Am. 301, 60-67. doi: 10.1038/scientificamerican0709-60

MacNeilage, P. F. (2007). The evolution of hemispheric specialization in primates. Spec. Top. Primatol. 5, 58-91.

MacNeilage, P. F., Studdert-Kennedy, M. G., and Lindblom, B. (1987). Primate handedness reconsidered. Behav. Brain Sci. 10, 247-303. doi: 10.1017/ S0140525X00047695

Mandal, M. K. (1999). Cultural difference in hand preference: evidence from India and Japan. Int. J. Psychol. 34, 59-66. doi: 10.1080/002075999400104

Marchant, L. F., and McGrew, W. C. (1996). Laterality of limb function in wild chimpanzees of Gombe National Park: comprehensive study of spontaneous activities. J. Hum. Evol. 30, 427-443. doi: 10.1006/jhev.1996.0036

Marchant, L. F., and McGrew, W. C. (1998). Human handedness: an ethological perspective. Hum. Evol. 13, 221-228. doi: 10.1007/BF02436506

Marchant, L. F., McGrew, W. C., and Eibl-Eibesfeldt, I. (1995). Is human handedness universal? ethological analyses from three traditional cultures. Ethology 101, 239-258. doi: 10.1111/j.1439-0310.1995.tb00362.x

McManus, I. C. (2002). Right Hand, Left Hand: The Origins of Asymmetry in Brains, Bodies, Atoms, and Cultures. London: Weidenfeld \& Nicolson.

McManus, I. C. (2010). Handedness, language dominance and aphasia: a genetic model. Psychol. Med. Monogr. Suppl. 8, 3. doi: 10.1017/S0264180100001879

McManus, I. C., and Bryden, M. P. (1992). "The genetics of handedness, cerebral dominance and lateralization," in Handbook of Neuropsychology, eds I. Rapin and S. J. Segalowitz (Amsterdam: Elsevier), 115-144.

McManus, I. C., Davison, A., and Armour, J. A. L. (2013). Multilocus genetic models of handedness closely resemble single-locus models in explaining family data and are compatible with genome-wide association studies. Ann. N. Y. Acad. Sci. 1288, 48-58. doi: 10.1111/nyas.12102

Medland, S. E., Duffy, D. L., Wright, M. J., Geffen, G. M., Hay, D. A., Levy, F., et al. (2010). Genetic influences on handedness: data from 25,732 Australian and Dutch twin families. Neuropsychologia 47, 330-337. doi: 10.1016/ j.neuropsychologia.2008.09.005

Meguerditchian, A., and Vauclair, J. (2006). Baboons communicate with their right hand. Behav. Brain Res. 171, 170-174. doi: 10.1016/j.bbr.2006.03.018

Meguerditchian, A., Vauclair, J., and Hopkins, W. D. (2013). On the origins of human handedness and language: a comparative review of hand preferences for bimanual coordinated actions and gestural communication in nonhuman primates. Dev. Psychobiol. 55, 637-650. doi: 10.1002/dev.21150

Mercola, M., and Levin, M. (2001). Left-right asymmetry determination in vertebrates. Annu. Rev. Cell Dev. Biol. 17, 779-805. doi: 10.1146/annurev.cellbio.17. 1.779

Meunier, H., Vauclair, J., and Fagard, J. (2012). Human infants and baboons show the same pattern of handedness for a communicative gesture. PLoS ONE 7:e33959. doi: 10.1371/journal.pone.0033959

Nettle, D. (2003). Hand laterality and cognitive ability: a multiple regression approach. Brain Cogn. 52, 390-398. doi: 10.1016/S0278-2626(03)00187-8

Neveu, P. J., Barnéoud, P., Vitiello, S., Betancur, C., and Le Moal, M. (1988). Brain modulation of the immune system: association between lymphocyte responsiveness and paw preference in mice. Brain Res. 457, 392-394. doi: 10.1016/ 0006-8993(88)90714-7

Nicholls, M. E. R., Chapman, H. L., Loetscher, T., and Grimshaw, G. M. (2010). The relationship between hand preference, hand performance, and general cognitive ability. J. Int. Neuropsychol. Soc. 16, 585-592. doi: 10.1017/S1355617710000184

Ocklenburg, S., Beste, C., and Arning, L. (2014a). Handedness genetics: considering the phenotype. Front. Psychol. 5:1300. doi: 10.3389/fpsyg.2014.01300
Ocklenburg, S., Beste, C., Arning, L., Peterburs, J., and Güntürkün, O. (2014b). The ontogenesis of language lateralization and its relation to handedness. Neurosci. Biobehav. Rev. 43, 191-198. doi: 10.1016/j.neubiorev.2014.04.008

Ocklenburg, S., Bürger, C., Westermann, C., Schneider, D., Biedermann, H., and Güntürkün, O. (2010). Visual experience affects handedness. Behav. Brain Res. 207, 447-451. doi: 10.1016/j.bbr.2009.10.036

Oldfield, R. C. (1971). The assessment and analysis of handedness: the edinburgh inventory. Neuropsychologia 9, 97-113. doi: 10.1016/0028-3932(71)90067-4

Oliveira, R. F., and Custodio, M. R. (1998). Claw size, waving display and female choice in the European fiddler crab, Uca tangeri. Ethol. Ecol. Evol. 10, 241-251. doi: 10.1080/08927014.1998.9522855

Palmer, A. R. (2009). Animal asymmetry. Curr. Biol. 19, R473-R477. doi: 10.1016/ j.cub.2009.04.006

Palmer, A. R. (2012). Developmental origins of normal and anomalous random right-left asymmetry: lateral inhibition versus developmental error in a threshold trait. Contrib. Zool. 81, 111-124.

Pascual, A., Huang, K., Neveu, J., Préat, T., Mecsas, J., Franklin, G., et al. (2004). Brain asymmetry and long-term memory. Nature 427, 10-11. doi: 10.1038/ $427605 a$

Perelle, I. B., and Ehrman, L. (1994). An international study of human handedness: the data. Behav. Genet. 24, 217-227. doi: 10.1007/BF01067189

Perlaki, G., Horvath, R., Orsi, G., Aradi, M., Auer, T., Varga, E., et al. (2013). Whitematter microstructure and language lateralization in left-handers: a whole-brain MRI analysis. Brain Cogn. 82, 319-328. doi: 10.1016/j.bandc.2013.05.005

Porac, C., and Coren, S. (1981). Lateral Preferences and Human Behaviour. New York: Sprinnger-Verlag.

Quaranta, A., Siniscalchi, M., Frate, A., and Vallortigara, G. (2004). Paw preference in dogs: relations between lateralised behaviour and immunity. Behav. Brain Res. 153, 521-525. doi: 10.1016/j.bbr.2004.01.009

Raczkowski, D., Kalat, J. W., and Nebes, R. (1974). Reliability and validity of some handedness questionnaire items. Neuropsychologia 12, 43-47. doi: 10.1016/0028-3932(74)90025-6

Raymond, M., and Pontier, D. (2004). Is there geographical variation in human handedness? Laterality 9, 35-51. doi: 10.1080/13576500244000274

Raymond, M., Pointier, D., Dufour, A.-B., and Pape Moller, A. (1996). Frequencydependent maintenance of left handeness in humans. Proc. R. Soc. B Biol. Sci. 263, 1627-1633. doi: 10.1098/rspb.1996.0238

Rockman, M. V. (2012). The QTN program and the alleles that matter for evolution: all that's gold does not glitter. Evolution 66, 1-17. doi: 10.1111/j.15585646.2011.01486.x

Rogers, L. J. (1980). Lateralisation in the avian brain. Bird Behav. 2, 1-12. doi: $10.3727 / 015613880791573835$

Rogers, L. J. (2002). Lateralization in vertebrates: its early evolution, general pattern, and development. Adv. Study Behav. 31, 107-161. doi: 10.1016/S00653454(02)80007-9

Rogers, L. J. (2009). Hand and paw preferences in relation to the lateralized brain. Philos. Trans. R. Soc. Lond. B Biol. Sci. 364, 943-954. doi: 10.1098/rstb.2008. 0225

Rogers, L. J. (2010). Relevance of brain and behavioural lateralization to animal welfare. Appl. Anim. Behav. Sci. 127, 1-11. doi: 10.1016/j.applanim.2010.06.008

Rogers, L. J., and Andrew, R. J. (eds). (2002). Comparative Vertebrate Lateralization. Cambridge: Cambridge University Press.

Rogers, L. J., Vallortigara, G., and Andrew, R. J. (2013). Divided Brains: The Biology and Behaviour of Brain Asymmetries. Cambridge: Cambridge University Press.

Ruppert, E. E., Fox, R. S., and Barnes, R. D. (2004). Invertebrate zoology: a functional evolutionary approach. Syst. Biol. 53, 662-664. doi: 10.1080/ 10635150490472977

Sarringhaus, L. A., Stock, J. T., Marchant, L. F., and McGrew, W. C. (2005). Bilateral asymmetry in the limb bones of the chimpanzee (Pan troglodytes). Am. J. Phys. Anthropol. 128, 840-845. doi: 10.1002/ajpa.20190

Scerri, T. S., Brandler, W. M., Paracchini, S., Morris, A. P., Ring, S. M., Richardson, A. J., et al. (2011). PCSK6 is associated with handedness in individuals with dyslexia. Hum. Mol. Genet. 20, 608-614. doi: 10.1093/hmg/ddq475

Sommer, I., Ramsey, N., Kahn, R., Aleman, A., and Bouma, A. (2001). Handedness, language lateralisation and anatomical asymmetry in schizophrenia: metaanalysis. Br. J. Psychiatry 178, 344-351. doi: 10.1192/bjp.178.4.344

Steenhuis, R. E., Bryden, M. P., Schwartz, M., and Lawson, S. (1990). Reliability of hand preference items and factors. J. Clin. Exp. Neuropsychol. 12, 921-930. doi: $10.1080 / 01688639008401031$ 
Stock, J. T., Shirley, M. K., Sarringhaus, L. A., Davies, T. G., and Shaw, C. N. (2013). Skeletal evidence for variable patterns of handedness in chimpanzees, human hunter-gatherers, and recent British populations. Ann. N. Y. Acad. Sci. 1288, 8699. doi: 10.1111/nyas.12067

Stoyanov, Z., Decheva, L., Pashalieva, I., and Nikolova, P. (2011). Brain asymmetry, immunity, handedness. Cent. Eur. J. Med. 7, 1-8. doi: 10.2478/s11536-0110121-2

Ströckens, F., Güntürkün, O., and Ocklenburg, S. (2013). Limb preferences in nonhuman vertebrates. Laterality 18, 536-575. doi: 10.1080/1357650X.2012.723008

Tommasi, L., and Vallortigara, G. (1999). Footedness in binocular and monocular chicks. Laterality 4, 89-95. doi: 10.1080/713754325

Uomini, N. T. (2011). "Handedness in neanderthals," in Neanderthal Lifeways, Subsistence and Technology: One Hundred Fifty Years of NEANDERTHALS Study, Vertebrate Vertebrate Paleobiology and Paleoanthropology, eds N. J. Conard and J. Richter (New York: Springer), 139-154. doi: 10.1007/978-94-0070415-2

Vaid, J., Bellugi, U., and Poizner, H. (1989). Hand dominance for signing: clues to brain lateralization of language. Neuropsychologia 27, 949-960. doi: 10.1016/ 0028-3932(89)90070-5

Vallortigara, G. (2000). Comparative neuropsychology of the dual brain: a stroll through animals' left and right perceptual worlds. Brain Lang. 73, 189-219. doi: 10.1006/brln.2000.2303

Vallortigara, G., and Bisazza, A. (2002). "How ancient is brain lateralization," in Comparative Vertebrate Lateralization, eds L. J. Rogers and R. Andrew (Cambridge: Cambridge University Press), 9-69.

Vallortigara, G., Chiandetti, C., and Sovrano, V. A. (2011). Brain asymmetry (animal). Wiley Interdiscip. Rev. Cogn. Sci. 2, 146-147. doi: 10.1002/wcs.100

Vallortigara, G., Rogers, L. J., and Bisazza, A. (1999). Possible evolutionary origins of cognitive brain lateralization. Brain Res. Rev. 30, 164-175. doi: 10.1016/ S0165-0173(99)00012-0

Vallortigara, G., Rogers, L. J., Bisazza, A., Lippolis, G., and Robins, A. (1998). Complementary right and left hemifield use for predatory and agonistic behaviour in toads. Neuroreport 9, 3341-3344. doi: 10.1097/00001756-19981005000035

Vauclair, J., Meguerditchian, A., and Hopkins, W. D. (2005). Hand preferences for unimanual and coordinated bimanual tasks in baboons (Papio anubis). Cogn. Brain Res. 25, 210-216. doi: 10.1016/j.cogbrainres.2005.05.012

Warren, D. M., Stern, M., Duggirala, R., Dyer, T. D., and Almasy, L. (2006). Heritability and linkage analysis of hand, foot, and eye preference in Mexican Americans. Laterality 11, 508-524. doi: 10.1080/13576500600761056
Weir, A. A. S., Kenward, B., Chappell, J., and Kacelnik, A. (2004). Lateralization of tool use in New Caledonian crows (Corvus moneduloides). Proc. R. Soc. B Biol. Sci. 271(Suppl.), S344-S346. doi: 10.1098/rsbl.2004.0183

Wells, D. L., and Millsopp, S. (2009). Lateralized behaviour in the domestic cat, Felis silvestris catus. Anim. Behav. 78, 537-541. doi: 10.1016/j.anbehav.2009.06.010

Westergaard, G. C., Chavanne, T. J., Lussier, I. D., Houser, L., Cleveland, A., Suomi, S. J., et al. (2003). Left-handedness is correlated with CSF monoamine metabolite and plasma cortisol concentrations, and with impaired sociality, in free-ranging adult male rhesus macaques (Macaca mulatta). Laterality 8, 169187. doi: 10.1080/713754484

Westergaard, G. C., Kuhn, H. E., and Suomi, S. J. (1998). Bipedal posture and hand preference in humans and other primates. J. Comp. Psychol. 112, 55-64. doi: 10.1037/0735-7036.112.1.55

Westergaard, G. C., Lussier, I. D., Suomi, S. J., and Higley, J. D. (2001). Stress correlates of hand preference in rhesus macaques. Dev. Psychobiol. 38, 110-115. doi: 10.1002/1098-2302(200103)38:2<110::AID-DEV1003>3.0.CO;2-\#

Willems, R. M., Ozyürek, A., and Hagoort, P. (2007). When language meets action: the neural integration of gesture and speech. Cereb. Cortex 17, 2322-2333. doi: $10.1093 /$ cercor/bhll41

Wundram, I. J. (1986). Cortical motor asymmetry and hominid feeding strategies feeding strategies of early hominids. Hum. Evol. 1, 183-187. doi: 10.1007/BF02437494

Conflict of Interest Statement: The authors declare that the research was conducted in the absence of any commercial or financial relationships that could be construed as a potential conflict of interest.

Received: 08 December 2014; paper pending published: 17 January 2015; accepted: 15 February 2015; published online: 06 March 2015.

Citation: Versace E and Vallortigara G (2015) Forelimb preferences in human beings and other species: multiple models for testing hypotheses on lateralization. Front. Psychol. 6:233. doi: 10.3389/fpsyg.2015.00233

This article was submitted to Cognition, a section of the journal Frontiers in Psychology.

Copyright (C) 2015 Versace and Vallortigara. This is an open-access article distributed under the terms of the Creative Commons Attribution License (CC BY). The use, distribution or reproduction in other forums is permitted, provided the original author(s) or licensor are credited and that the original publication in this journal is cited, in accordance with accepted academic practice. No use, distribution or reproduction is permitted which does not comply with these terms. 